\title{
Tracheal Epithelium
}

National Cancer Institute

\section{Source}

National Cancer Institute. Tracheal Epithelium. NCI Thesaurus. Code C33797.

Pseudostratified ciliated columnar epithelium with many Goblet cells, lining the lumen of the trachea. The basement membrane is thick. 